\title{
Vulvovaginitis in a pediatric population: relationship among etiologic agents, age and Tanner staging of breast development
}

\author{
Dolores Ocampo, M.D., ${ }^{a}$ Gisel Rahman, M.D., ${ }^{a}$ Silvina Giugno, M.D., ${ }^{b}$ Paula Risso, M.D. , and \\ Anahí V. Rubinstein, M.D. ${ }^{a}$
}

\begin{abstract}
Introduction. Vulvovaginitis accounts for $25 \%$ of all pediatric gynecology consultations.

Objective. To assess the etiology of vulvovaginitis based on age and Tanner staging of breast development.

Material and Methods. Descriptive, cross-sectional study conducted between January $1^{\text {st }}$ and December $31^{\text {st }}, 2011$. Patients with vulvovaginitis were assessed based on two outcome measures: age group (GI: 0 to 8.9 years old, GII: 9 to 15.9 years old, and GIII: 16 to 18 years old), and the Tanner staging of breast development (I, II-III, IV-V).

Results. Two hundred and twenty-nine patients were included, 78 girls in the GI group, 134 in the GII group, and 17 in the GIII group; 81 girls were classified as TI, 36 as TII-III, and 112 as TIV-V based on Tanner staging. Shigella and Oxyuris were the most commonly found etiologic agents in younger girls. Candida albicans, other Candida species, Gardnerella and Ureaplasma urealyticum were the germs most commonly observed in older patients. Oxyuris was predominant in prepubertal girls, while Candida albicans, in postpubertal girls.

Conclusions. Hormonal influence was more relevant than the patient's age in terms of vulvovaginitis etiology.

Key words: vulvovaginitis, childhood, adolescence, age, breast development stages.
\end{abstract}

http:/ /dx.doi.org/10.5546/aap.2014.eng.65

\section{INTRODUCTION}

Vulvovaginitis is defined as an inflammation of the vulvovaginal mucous membranes. ${ }^{1}$ It accounts for $25 \%$ of all pediatric gynecology

a. Pediatric and Adolescent Gynecology Unit of Hospital Sor María Ludovica, La Plata, Buenos Aires.

b. Microbiology Laboratory of Hospital Sor María Ludovica, La Plata, Buenos Aires.

c. Chair of Bayesian and Classical Biostatistics at the Clinical and Industrial Microbiology Degree, Epizootiology and Public Health Department, School of Veterinary Medicine.

E-mail address:

Dolores Ocampo, M.D.: doloresocampo72@gmail.com

Conflict of Interest:

None.

Received: 03-11-2013

Accepted: 07-22-2013 consultations. ${ }^{2}$ Decreased estrogen stimulus during the prepubertal period results in thinning of the vulvovaginal epithelium, local alkaline $\mathrm{pH}$ and thin labia minora, all factors that favor the development of vulvovaginitis. This disease accounts for $23 \%$ of all consultations made at our Pediatric and Adolescent Gynecology Unit. Among prepubertal girls, the most common clinical presentation is nonspecific vulvovaginitis (NSVV) caused by endogenous vaginal flora, which can become aggressive due to decreased mucous membrane integrity and physicochemical alterations.

Specific vulvovaginitis (SVV) is associated with a particular etiologic agent, grouped according to its respiratory, enteral or sexuallytransmitted origin. ${ }^{3}$ Little has been published in the literature regarding the relationship between the different etiologies and pubertal development. ${ }^{4}$

The objective of this study is to describe the etiology of vulvovaginitis in terms of age and estrogen stimulus in girls examined at our unit as part of walk-in consultations.

\section{MATERIAL AND METHODS}

All patients with vulvovaginitis examined at the Pediatric and Adolescent Gynecology Unit of Hospital Sor María Ludovica of La Plata between January $1^{\text {st }}$ and December $31^{\text {st }}, 2011$ were included. Their medical history and physical and gynecological exams were recorded in the presence of an adult caregiver. Estrogen stimulus was assessed based on Marshall and Tanner staging of breast development. ${ }^{5}$ Patients with chronic conditions referred by other specialties and those suspected of sexual abuse were excluded. An intravaginal discharge sample was collected with a swab from patients with genital secretions at the time of the assessment. Tests performed included a fresh smear, Gram staining, common germ culture, and direct immunofluorescence for Chlamydia trachomatis and Ureaplasma urealyticum. No cultures were taken from patients with signs and symptoms of 
oxyuriasis: anogenital and nasal pruritus, bruxism and perineogenital congestion. Diagnosis was established as per the recommendations in the Manual of the Sociedad Argentina de Ginecología Infanto Juvenil. ${ }^{3}$

\section{Statistical method}

Descriptive, cross-sectional study. Patients were grouped by age: GI (0 to 8.9 years old), GII (9 to 15.9 years old), and GIII (16 to 18 years old), and by breast development stage: Tanner I stage (TI); Tanner II-III stage (TII-III), and Tanner IV-V stage (TIV-V). Different $2 \times 2$ contingency tables were developed to test the association between positive cases and the corresponding age and Tanner stage groups. Age groups and germ types were assessed using the $X^{2}$ test. ${ }^{6}$ The confidence interval was set at $95 \%$ (alpha error $\leq 0.05$ ). The Epidat $3.1^{\circledR}$ software was used.?

Ethical considerations: this was a retrospective study, so it was not possible to obtain an informed consent. Data were anonymized. The study was approved by the hospital's Teaching and Research Board.

\section{RESULTS}

\section{Relationship between etiology and age}

A total of 229 patients were analyzed: 78 patients from the GI group ( $6 \pm 2$ years old $), 134$ from the GII group (12.6 \pm 1.8 years old $)$, and 17 from the GIII group (16.7 \pm 0.7 years old). Given the small size of group GIII, it was excluded from the statistical analysis. The etiologies of nonspecific vulvovaginitis were Oxyuris and mixed flora vulvovaginitis (MFVV); the etiologic agents of specific vulvovaginitis were Shigella sp., Haemophylus influenzae, Candida albicans, other Candida species, Escherichia coli, Staphylococcus, Streptococcus pyogenes, Streptococcus agalactiae, Streptococcus pneumoniae, Chlamydia trachomatis, Gardnerella vaginalis, Trichomonas, Ureaplasma urealyticum, Mycoplasma and herpes virus 1. Significant differences were observed for Oxyuris $(p<0.0001)$ and Shigella $(p=0.0047)$ between the GI and GII groups, with a higher percentage of positive cases among younger girls versus older girls (Figure 1). On the contrary, Candida albicans, Gardnerella, Ureaplasma, and other Candida species were more common among older than younger patients, showing significant differences (Figure 1). In group GIII, positive cases were recorded only for Oxyuris $(\mathrm{n}=3)$, Chlamydia trachomatis $(\mathrm{n}=1)$, Gardnerella $(\mathrm{n}=2)$, MFVV $(\mathrm{n}=1)$, Trichomonas $(\mathrm{n}=1)$ and Candida $(\mathrm{n}=1)$.

In the GI group, the most common germs were Oxyuris (47.4\%) and MFVV (26.9\%); while in the GII group, the most frequent ones were MFVV $(23.1 \%)$, other Candida species (22.3\%), Candida

TABLE 1. Comparison of germs by Tanner stages I, II-III and IV-V using the $X^{2}$ test

\begin{tabular}{|c|c|c|c|c|c|}
\hline Etiology & Tanner stage & Positive cases (n) & Comparison & $X^{2}$ & p-value \\
\hline \multirow[t]{3}{*}{ Oxiurus sp. } & I & 40 & I vs. II-III & 1.77 & 0.1832 \\
\hline & II-III & 13 & I vs. IV-V & 59.21 & $<0.0001^{*}$ \\
\hline & IV-V & 3 & II-III vs. IV-V & 28.21 & $<0.0001^{*}$ \\
\hline \multirow[t]{3}{*}{ U. urealyticum } & I & 0 & I vs. II-III & 0.18 & 0.6756 \\
\hline & II-III & 1 & I vs. IV-V & 17.04 & $<0.0001^{*}$ \\
\hline & IV-V & 21 & II-III vs. IV-V & 5.49 & $0.0191^{*}$ \\
\hline \multirow[t]{3}{*}{ C. albicans } & I & 0 & I vs. II-III & 3.99 & $0.0457^{*}$ \\
\hline & II-III & 3 & I vs. IV-V & 17.04 & $<0.0001^{*}$ \\
\hline & IV-V & 21 & II-III vs. IV-V & 2.18 & 0.1402 \\
\hline \multirow[t]{3}{*}{ Other Candida species } & I & 2 & I vs. II-III & 0.36 & 0.5482 \\
\hline & II-III & 6 & I vs. IV-V & 15.40 & $0.0001^{*}$ \\
\hline & IV-V & 25 & II-III vs. IV-V & 0.53 & 0.4683 \\
\hline \multirow[t]{3}{*}{ G. vaginalis } & I & 0 & I vs. II-III & 1.87 & 0.1716 \\
\hline & II-III & 2 & I vs. IV-V & 5.92 & $0.0150^{*}$ \\
\hline & IV-V & 10 & II-III vs. IV-V & 0.09 & 0.7687 \\
\hline \multirow{3}{*}{ Shigella sp. } & I & 6 & I vs. II-III & 1.49 & 0.2215 \\
\hline & II-III & 0 & I vs. IV-V & 6.28 & $0.0122^{*}$ \\
\hline & IV-V & 0 & II-III vs. IV-V & & \\
\hline
\end{tabular}

Cells marked with an asterisk $(*)$ and in grey show significant differences $(\mathrm{p} \leq 0.05)$. The black cell indicates a null comparison that cannot be subjected to a statistical analysis. No significant differences were found for MFVV, Haemophylus influenzae, E. coli, Staphyloccus sp., S. pyogenes, S. agalactiae, C. trachomatis, Trichomonas and Mycoplasma species, herpes virus 1, and S. pneumoniae $(\mathrm{p}>0.05)$. 
albicans (17.9\%), Ureaplasma (16.4\%) and Oxyuris (11.9\%) (Figure 1).

\section{Relationship between the etiology and Tanner stage}

In terms of Tanner stage, 82 patients were classified as TI, 36 as TII-III, and 112 as TIV-V. Significant differences were observed for Oxyuris: the number of positive cases in the TI stage $(\mathrm{p}<0.0001)$ and TII-III stage $(\mathrm{p}<0.0001)$ was significantly higher compared to the TIV-V stage; as a result, a decreasing positivity degree, from TI to TIV-V, was recorded. Significant differences were observed between the TI and TIV-V groups $(\mathrm{p}=0.012)$ for Shigella, with all cases found in the TI group. For Candida albicans, significant differences were found between TI and TII-III $(p=0.0457)$ and between TI and TIV-V $(\mathrm{p}<0.0001)$, with a reverse pattern for Oxyuris. Other Candida species $(\mathrm{p}=0.0001)$ and Gardnerella $(p=0.015)$ were the etiologies recorded in a significantly higher number of cases in the TIV-V group versus the TI group. Cases of Ureaplasma were significantly higher in the TIV-V stage compared to the TI $(\mathrm{p}<0.0001)$ and the TII-III stages $(\mathrm{p}=0.0191)$.

The percent frequency of etiologies was assessed in relation to the total number of patients for each puberty category (Figure 2). All Shigella cases were found in the TI stage, while Mycoplasma and herpes virus 1 were observed only in the TIV-V stage; however, MFVV was observed across the three stages. The highest number of different etiologic agents was recorded in the TIV-V stage (Table 2).

Among the 21 patients who were already sexually active, 35\% presented Ureaplasma, 29\% had Candida albicans and 29\% had Gardnerella. Taking into consideration the relationship between age and Tanner stages, neither the TI stage nor the GI group showed sexuallytransmitted germs, except for Chlamydia trachomatis, which was found in one case corresponding to the GI groups and TII-III stage.

\section{DISCUSSION}

Vulvovaginitis during childhood and adolescence is a common reason for consultation. In our series, and consistent with some other authors' findings, nonspecific vulvovaginitis accounted for approximately $77 \%$ of all vulvovaginitis cases in prepubertal girls. ${ }^{3}$ However, MFVV was frequent in all pubertal development stages. In relation to specific

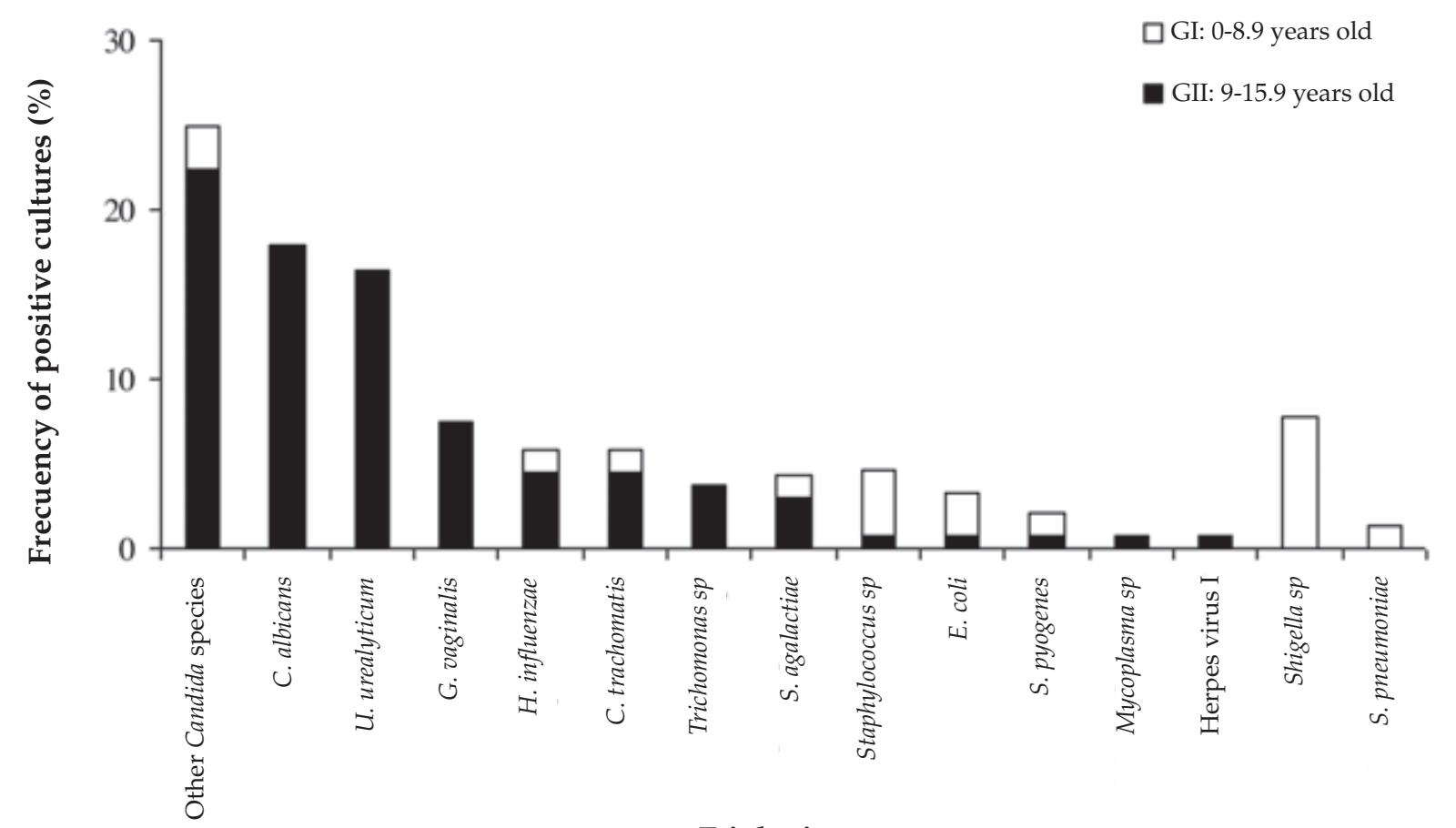

Etiologies 
FIgURE 2. Percent frequency of patients with positive cultures for specific vulvovaginitis in relation to Tanner staging (TI, TII-III and TIV-V)



Etiologies

TABLE 2. Percentage of patients with positive cultures in relation to Tanner staging (TI, TII-III and TIV-V).

The value between brackets shows the number of cases

\begin{tabular}{|c|c|c|c|c|c|}
\hline Etiology & T I & Etiology & T II-III & Etiology & T IV-V \\
\hline Oxiurus sp & $51.95(40)$ & Oxiurus sp & $30.95(13)$ & Other Candida & $19.84(25)$ \\
\hline NSVV & $25.97(20)$ & NSVV & $21.43(9)$ & NSVV & $19.05(24)$ \\
\hline Shigella sp & $7.79(6)$ & Other Candida & $14.29(6)$ & C. albicans & $16.67(21)$ \\
\hline H. influenzae & $2.60(2)$ & H. influenzae & $7.14(3)$ & Ureaplasma sp & $16.67(21)$ \\
\hline E. coli & $2.60(2)$ & C. albicans & $7.14(3)$ & G. vaginalis & $7.94(10)$ \\
\hline Other Candida & $2.60(2)$ & Chlamydia sp & $4.76(2)$ & Chlamydia sp & $5.56(7)$ \\
\hline Staphylococcus sp & $2.60(2)$ & G. vaginalis & $4.76(2)$ & Trichomonas sp & $3.97(5)$ \\
\hline S. pyogenes & $1.30(1)$ & Staphylococcus sp & $2.38(1)$ & Oxiurus sp & $2.38(3)$ \\
\hline S. pneumoniae & $1.30(1)$ & S. agalactiae & $2.38(1)$ & S. agalactiae & $2.38(3)$ \\
\hline S. agalactiae & $1.30(1)$ & Trichomonas sp & $2.38(1)$ & H. influenzae & $1.59(2)$ \\
\hline C. albicans & $0.00(0)$ & Ureaplasma sp & $2.38(1)$ & E. coli & $0.79(1)$ \\
\hline Chlamydia sp & $0.00(0)$ & Shigella $s p$ & $0.00(0)$ & Staphylococcus sp & $0.79(1)$ \\
\hline G. vaginalis & $0.00(0)$ & E. coli & $0.00(0)$ & S. pyogenes & $0.79(1)$ \\
\hline Trichomonas sp & $0.00(0)$ & S. pyogenes & $0.00(0)$ & Mycoplasma sp & $0.79(1)$ \\
\hline Ureaplasma sp & $0.00(0)$ & S. pneumoniae & $0.00(0)$ & Herpes virus I & $0.79(1)$ \\
\hline Mycoplasma sp & $0.00(0)$ & Mycoplasma sp & $0.00(0)$ & Shigella $s p$ & $0.00(0)$ \\
\hline Herpes virus I & $0.00(0)$ & Herpes virus I & $0.00(0)$ & S. pneumoniae & $0.00(0)$ \\
\hline
\end{tabular}


vulvovaginitis, certain pathogens were associated with a specific Tanner breast development stage, which indicates that such pathogens are mainly related to a specific estrogen level., ${ }^{4,7}$ This is the case of the Shigella genus in prepubertal patients, which has been recorded only in the context of an alkaline $\mathrm{pH}$, characteristic of this stage. ${ }^{3,7}$

Gryngarten, et al. published that the germs responsible for most specific vulvovaginitis are respiratory tract pathogens (Haemophilus influenzae and Streptoccocus pyogenes), which cause mucopurulent discharge after the onset of menarche. ${ }^{8-10}$ Notwithstanding this, in our study, we found that Shigella was most common in patients with vulvovaginitis and bleeding, followed by Escherichia coli. Such high prevalence can be explained by poor hygiene in the studied population.

In the late stages of development, when there is an estrogen stimulus, the most common cases were due to Candida albicans and other Candida species given that fungi tend to have a higher adherence to the vulvovaginal epithelium due to the hormonal action. ${ }^{11}$

Some etiologies were more common in the younger age group, e.g. Shigella and Oxyuris. In relation to Oxyuris, and in agreement with other authors, given that it is difficult to make an etiological diagnosis using a Graham's test with a relatively low recovery rate, an empiric treatment is warranted whenever patients have a consistent medical history and clinical condition. ${ }^{8,12}$ Candida albicans, other Candida species, Gardnerella and Ureaplasma were commonly found in girls older than 9 years old. ${ }^{13,14}$

In the case of Chlamydia trachomatis (one positive result in the younger age group), the patient was assessed by an interdisciplinary team, who ruled out the suspicion of sexual abuse. Although this pathogen is associated with abuse, there are other modes of transmission, such as oropharyngeal, conjunctival or mother-to-child. 2,15 The germs observed in the patients who were sexually active can be related to such activity.

Among the study's strengths, we could mention that it delves deep into the relationship between pubertal development stage and vulvovaginitis etiology, a topic that has been scarcely published in the literature, and the number of thoroughly studied patients, which allowed us to make statistically valid conclusions.

However, in the study we did not analyze the relationship of cases with other concurrent pathologies, prior antibiotic therapy, and duration of symptoms, which should be assessed in future studies and could be of interest for all pediatricians. Sexual abuse consultations were not included in the analysis because most patients had received an empiric treatment at the primary care facilities, before attending our unit.

\section{CONCLUSIONS}

Hormonal influence was more relevant than the patient's age in terms of the etiology of vulvovaginitis. Pubertal development should be assessed at the time of recording a detailed medical history so as to establish the etiological diagnosis.

\section{REFERENCES}

1. Sánchez de la Cruz BE, Fleury C. Vulvovaginitis. En: Sánchez de la Cruz EB. Ginecología Infantojuvenil. Panamericana; 2011. Págs. 75-89.

2. Comité Nacional de Endocrinología. Recomendaciones para el diagnóstico y tratamiento de vulvovaginitis en niñas prepúberes. Arch Argent Pediatr 2000;98(6); 412-4.

3. Zeiguer N, Gryngarten M, Herbst M, Galvano A. Patología del tracto genital. Infecciones en la recién nacida y en la infancia. En: Sociedad Argentina de Ginecología Infanto juvenil. Manual de Ginecología Infanto Juvenil. Buenos Aires: Ascune; 2003. Págs. 305-16.

4. Gryngarten M, Escobar ME, Turco M. Vulvovaginitis en niñas y adolescentes: Agentes patógenos más frecuentes. Rev Hosp Niños BAires 2003;65(202):75-80.

5. MarshallW A, Tanner JM. Variations in patterns of pubertal changes in girls. Arch Dis Child 1986;140:24.

6. Sokal R R, Rohlf JF. Biometry: The Principles and Practice of Statistics in Biological Research. 2nd ed. New York, 1981.

7. Epidat3.1 para Windows Análisis Epidemiológico de Datos Tabulados. Programa desarrollado por la Xunta de Galicia y la Organización Panamericana de la Salud; 2004.

8. Stricker T, Navratil F, Sennhauser FH. Vulvovaginitis in prepubertal girls. Arch Dis Child 2003;88:324-6.

9. Cuadros J, Mazón A, Martínez R, González P, et al. The aetiology of paediatric inflammatory vulvovaginitis. Eur J Pediatr 2004;163(2):105-7.

10. Joishy M, Ashtekar CS, Jaim A, Gonsalves Rl. Do we need to treat vulvovaginitis in prepubertal girls. BMJ 2005;330:1868.

11. O'Brien TJ. Paediatric vulvovaginitis. Australas J Dermatol 1995;36(4):216-8.

12. Dei M, Di Maggio F, Di Paolo G, Bruni V. Vulvovaginitis in childhood. Best Pract Res Clin Obstet Gynaecol 2010. 24(2):129-37.

13. Barrenetxea Ziarrusta G. Vulvovaginitis candidiásica. Rev iberoam Micol 2002; 19:22-4.

14. Yilmaz A, Celik N, Soylu G, Yuksel C. Comparison of clinical and microbiological features of vulvovaginitis in prepubertal and pubertal girls. J Formos Med Assoc 2012; 111(7):392-6.

15. Lanjouw E, Ossewaarde JM, Stary A, Boag F, van der Meijden WI. 2010 European guideline for the management of Chlamydia trachomatis infections. Int J STD AIDS 2010;21(11):729-37. 